\title{
Mercado de Trabalho e Meio Ambiente no Brasil entre 2007 e 2014: a caminho do emprego verde?
}

\section{Stela Luiza de Mattos Ansanelli Luiz Henrique Bispo Santos²}

\begin{abstract}
Resumo: Neste artigo busca-se, por meio de uma análise empírica da evolução do número de empregos formais de 2007 a 2014, investigar as relações entre meio ambiente e mercado de trabalho, avaliando em quais setores se concentraram as contratações no Brasil e objetivando identificar o nível de qualificação e geração de renda. As atividades cujos impactos ambientais são negativos ainda são a maior fonte geradora de empregos, mas há um potencial de crescimento em atividades voltadas à preservação ambiental. Os empregos verdes são melhores, pois empregam mão de obra com maior nível de escolarização, mas não têm recebido os melhores rendimentos.
\end{abstract}

Palavras-chave: emprego verde, mercado de trabalho, Brasil, meio ambiente

Classificação JEL: J01; J40; Q01

Labor market and environment in Brazil between 2007 and 2014: on the path to the green job?

\begin{abstract}
This article attempts, through an empiric analysis of the evolution in the number of formal jobs between 2007 and 2014, to investigate relations between the environment and the labor market by evaluating in which sectors employments are concentrated in Brazil in order to identify the level of qualification and income generation. The activities whose environmental impacts are negative are still the main source of employment in our country, but there is a potential of growth in jobs directed to the environmental preservation. These green jobs are better, because they typically employ higher education employees, but they have not received the best income.
\end{abstract}

Keywords: green job, labor market, Brazil, environment

1 Doutora em Economia, Docente do Departamento de Economia da Universidade Estadual Paulista (UNESP) Júlio de Mesquita Filho. E-mail: stelaluiza@fclar.unesp.br.

2 Graduando em Ciências Econômicas pela Universidade Estadual Paulista (UNESP) Júlio de Mesquita Filho. E-mail: henrique.petrelli@hotmail.com. 


\section{Introdução}

Em 2007, surgiu a Iniciativa Empregos Verdes, uma parceria entre o Programa das Nações Unidas para o Meio Ambiente (PNUMA), Organização Internacional do Trabalho (OIT), Organização Internacional de Empregadores (OIE) e Confederação Sindical Internacional (CSI), com o objetivo de estudar as relações entre sustentabilidade e mercado de trabalho e orientar políticas econômicas voltadas para o tema.

Emprego verde pode ser considerado como a geração de empregos por parte de atividades associadas à conservação ambiental e se tornou o símbolo de uma economia baseada em novos padrões de consumo e produção, que exigem um redirecionamento para as atividades produtivas que respeitem a restrição imposta pelo meio ambiente.

As principais fontes criadoras destes tipos de postos de trabalho são a regulamentação ambiental e as políticas públicas (BAKKER; YOUNG, 2011). Apesar dos custos enfrentados pelas empresas para se adequar às regulamentações ambientais, sabe-se que, em muitos casos, os custos ambientais e de saúde já superaram os ganhos que a atividade econômica gerou. Isso mostra a necessidade de alterar o rumo de uma economia predatória em direção à economia verde, aquela que defende o desenvolvimento econômico com preservação ambiental e inclusão social (OIT, 2009; UNEP, 2008). A economia verde, portanto, gera possibilidades de ganhos triplos: econômicos, ambientais e sociais.

No Brasil, o processo de industrialização por substituição de importações privilegiou setores intensivos em emissões e o modelo de desenvolvimento atual tem sido nocivo, do ponto de vista ambiental, visto que as exportações se concentram em bens intensivos em recursos naturais e atividades poluentes. $\mathrm{O}$ complexo exportador é mais intensivo em emissões do que a média da indústria (YOUNG; LUSTOSA, 2001; LUSTOSA, 2014). No entanto, o avanço recente das medidas ambientais - como a Política Nacional de Resíduos Sólidos -, da questão do saneamento e dos investimentos em fontes de energia renováveis sugere que novas oportunidades possam emergir.

Além disso, poucas são as referências sobre a relação entre mercado de trabalho e meio ambiente no país. Com relação ao emprego verde, foi publicado um relatório da OIT (2009) que classificou e apresentou o número de postos de trabalho em atividades com impactos diretos ou indiretos sobre o meio ambiente no Brasil, em 2008, estimado em cerca de 6\% do emprego total. Bakker e Young (2011) discutiram algumas classificações e propuseram uma específica às idiossincrasias nacionais, que trata de empregos diretamente relacionados à preservação ambiental. No que se refere aos outros setores, não foram obtidos resultados com este foco. Bakker e Young (2011) apresentaram uma metodologia ampla que separa as categorias de atividades sujas, mas é muito agregada e não oferece resultados empíricos. Sabe-se também que o Banco Mundial, conforme Hettige et al. (1995), ressalta a 
importância de estabelecer uma associação entre emissão de poluição e número de empregados para classificar indústrias com alto potencial poluidor.

O objetivo deste trabalho é, portanto, investigar em quais setores se concentraram as contratações no Brasil entre 2007 e 2014: nas atividades econômicas que prejudicam o meio ambiente, nas atividades industriais limpas ou nas atividades econômicas voltadas à preservação ambiental? Que tipos de trabalho são esses, em termos de qualificação e geração de renda? Não só a resposta para estas perguntas, como também a metodologia diferenciada utilizada para tal - que propõe uma nova classificação dos setores conforme seu impacto ambiental, em consonância com códigos internacionais e nacionais de atividades econômicas - justificam a elaboração deste trabalho.

\section{Empregos verdes na transição para uma Economia Verde}

A crise econômica e ambiental, embora apresente um cenário recessivo em termos de crescimento econômico e de geração de emprego, pode se tornar um terreno fértil no que se refere à criação de oportunidades aos setores desenvolvedores de tecnologias ambientais e, consequentemente, de empregos sustentáveis. $\mathrm{Na}$ literatura, este tema é discutido no âmbito da transição de uma economia predatória para uma Economia Verde.

Até meados dos anos 1970-80, a proteção ambiental não era vista como parceira do crescimento econômico, de modo que as firmas viam custos adicionais na instalação de tecnologias ambientais. Assim, para sobreviver às crises econômicas, as empresas reduziam seus custos, sobretudo em termos de pessoal ocupado. Neste sentido, a reação à crise enfraqueceria práticas sustentáveis.

No entanto, podemos pensar que a crise é resultado de modos destrutivos de produção e consumo e falha no compromisso da distribuição social justa dos recursos e da riqueza (MONTEIRO; CORREAA FILHO; SIQUEIRA, 2010). Sob este ponto de vista, a crise ambiental é apenas um sintoma de um sistema econômico baseado em energias fósseis, na produção e no consumo em massa, no uso e na extração indiscriminados de recursos naturais, na expansão da fronteira agrícola, entre outros.

É neste cenário que emerge a iniciativa da Economia Verde e o conceito de emprego verde. Conforme UNEP (2008), a Economia Verde representa uma economia com crescente bem-estar social e capital humano, com queda significativa de riscos ambientais e ecológicos. Este conceito engloba práticas econômicas ambientalmente adequadas e socialmente equitativas. O conceito de Economia Verde não substitui o de desenvolvimento sustentável, mas o aperfeiçoa ao reconhecer que este deve ser alcançado por meio de mudanças nas políticas, corrigindo os rumos da economia.

Conforme observou Young (2014), a Economia Verde proporciona novas oportunidades para o investimento e a geração de emprego e renda. Neste sentido, 
inexiste trade-off entre sustentabilidade ambiental e progresso econômico, mas sim um "ganho-ganho", que exige políticas públicas e não se materializa espontaneamente. Nesse contexto, o emprego verde é aquele que reduz o impacto ambiental das empresas e dos setores econômicos. Conforme OIT (2009), ele pode estar presente na agricultura, manufatura, setor de serviços e administração, assim como nos segmentos de energia, construção e transporte.

A transição para a Economia Verde é, portanto, desejável e orientada pelos organismos internacionais. No entanto, há uma preocupação de como este processo deve ser realizado. Para Betini (2013), à medida que ações da economia verde sejam implementadas, a criação de empregos em indústrias poluidoras tende a cair. Da mesma forma, Sima (2014) afirma que o crescimento verde gera desafios no mercado de trabalho, como resultado da reestruturação industrial (queda da indústria poluidora e ascensão da indústria verde).

A indústria verde tem crescido significativamente. Evidências mostram que o setor tem gerado em torno de 319 bilhões de euros - cerca de 2,5\% do PIB - e correntemente emprega 3,4 milhões de pessoas. A taxa de crescimento anual do emprego nesse setor foi de $7 \%$ entre 2000 e 2008. A União Europeia (UE) representa $30 \%$ do mundial de tecnologias ambientais e, nos últimos anos, mais de um milhão de novos empregos verdes tem sido criados (SIMA, 2014).

Com relação aos outros setores, apesar dos desafios, Betini (2013) enxerga oportunidades de geração de emprego verde:

- agricultura: setor que emprega mundialmente trabalhadores rurais e de subsistência, o que exige investimentos em infraestrutura e treinamento para práticas de produção verde;

- indústria florestal: as perdas derivadas das práticas insustentáveis implicam a modernização do setor em direção ao manejo sustentável;

- energia: os combustíveis fósseis representaram $87 \%$ do uso comercial de energia em 2010, enquanto que a renovável e nuclear, $8 \%$ e $5 \%$, respectivamente. No entanto, o primeiro setor emprega pouco, já os empregos (diretos e indiretos) criados nas atividades renováveis mais do que dobraram entre 2008 e 2010;

- reciclagem: apesar do crescimento desta atividade, há necessidade de formalização dos postos de trabalho, uma vez que grande parte é composta por mulheres e crianças;

- transporte: é um grande consumidor de combustíveis fósseis e representa $25 \%$ das emissões de dióxido de carbono (CO2), contudo há oportunidades de esverdeamento no desenvolvimento de veículos híbridos e elétricos.

Desta forma, a transição para a economia verde não pode ser abrupta, mas sim planejada pelo governo para que a sociedade, como um todo, não sofra.

O documento da Organização Econômica para Cooperação e Desenvolvimento (OCDE, 2009) citou quatro possibilidades para que a crise de 2008 fosse aproveitada e promovesse a transição para uma economia verde. São elas: remover subsídios existentes na produção e no consumo de energia baseada em fósseis; rea- 
lizar cortes nas barreiras comerciais para os produtos amigáveis ao clima; melhorar a eficiência dos sistemas de transporte e construção e fazer reformas políticas com objetivo ambiental e melhor custo-efetividade.

Mas, quais seriam, em específico, as atividades verdes nas quais são criados os postos de trabalho? Neste aspecto não há um consenso metodológico quanto à classificação destas atividades. A OIT (2009) repartiu a análise de emprego verde em dois grupos: o das atividades que contribuem para a redução do efeito estufa e para a preservação da qualidade ambiental (produção, manejo, geração e distribuição de energia, saneamento, transporte coletivo, telecomunicações, entre outras) e o das atividades extrativas que dependem da qualidade ambiental (extração mineral e indústria de base, construção, agricultura, pecuária, pesca, entre outras).

O Sistema de Classificação da Indústria Norte-Americana (NAICS) selecionou as atividades de bens e serviços verdes para que se pudessem acompanhar efeitos de políticas públicas sobre o emprego verde, por meio da abordagem do produto (estabelecimentos que produzem bens e serviços verdes) e do processo (práticas de gestão ambiental). Estas ações incluem cultivo de produtos orgânicos, produção e geração de energia renovável, reciclagem, entre outros (FEDERAL REGISTER, 2010 apud BAKKER; YOUNG, 2011).

Bakker e Young (2011), a partir das classificações internacionais, destacaram as dificuldades em separar empregos que possuem relação direta com a qualidade ambiental daqueles que não a possuem. $\mathrm{Na}$ visão dos autores, grande parte dos empregos que seriam considerados verdes, pelas abordagens da OIT e da NAICS, não podem ser classificados como tal no Brasil, porque se referem a setores responsáveis por muitos danos ambientais causados por práticas de produção. Por exemplo, não é possível saber se a extração de madeira foi realizada de forma predatória ou sustentável. Assim, os autores propõem que as atividades criadoras de empregos verdes devam ser aquelas diretamente relacionadas à preservação ambiental, como tratamento de água, esgoto e resíduos. A caracterização da relação entre emprego e meio ambiente no Brasil será apresentada na próxima seção.

\section{0 contexto nacional: industrialização, meio ambiente e mercado de trabalho}

Ao longo do século XX, a participação da indústria no Produto Interno Bruto (PIB) superou a participação da agricultura nos anos 1950 e, no período do "milagre econômico" (1968-1973), o crescimento industrial foi significativo, em torno de $13 \%$ ao ano. O II Plano Nacional de Desenvolvimento (II PND), em 1975, promoveu uma profunda transformação na indústria brasileira com a ascensão das atividades de Bens Intermediários (BI), como química, petroquímica, metal mecânica, metalúrgica, papel e celulose, entre outras. A participação do setor no valor da produção corrente passou de $21 \%$, em 1950 , para $43 \%$ em 1975 . Apesar do avanço na instalação do parque produtivo, a industrialização brasileira gerou pressões am- 
bientais, pois estas atividades são as mais poluentes e intensivas em recursos naturais do que a média das indústrias de transformação.

Nos anos 1980, a estratégia de redução dos déficits comerciais gerou coeficientes de emissão do complexo exportador maiores do que a média de outras categorias. $\mathrm{O}$ crescimento desta produção predatória, diante da lentidão no estabelecimento de normas ambientais, intensificou-se após a abertura comercial, visto que o país se especializou na exportação de bens intensivos, recursos naturais e energia e em atividades de elevado potencial poluidor (BARCELLOS, 2001; YOUNG, 2014). Em contrapartida, as atividades que mais foram exportadas nos anos 2000 foram aquelas com menor intensidade tecnológica (GRAMKOW, 2011).

Evidências mostraram que entre 1981 e 1999, o produto industrial com alto potencial poluidor aumentou 50\% (YOUNG; LUSTOSA, 2001); o setor de BI foi responsável por cerca de 90\% das emissões de Dióxido de Enxofre (SO2), 80\% de Dióxido de Nitrogênio (NO2) e quase 100\% de Particulados Finos (PF) em 1996 (YOUNG; PEREIRA; HARTJE, 2000); e consumiu cerca de 50\% do total de energia demandado pela indústria como um todo em 1999 (BARCELLOS, 2001). Com relação ao comércio, mais de $2 / 3$ das exportações industriais, entre 1996 e 2007, originou-se de setores com alto potencial poluidor (LUSTOSA, 2008); as atividades exportadoras geraram um aumento de $56 \%$ das emissões de Gases do Efeito Estufa (GEE), entre 1990 e 2005 (GRAMKOW, 2011), e, recentemente, após 2006, mais de $50 \%$ das exportações brasileiras para a China apresentaram alto potencial poluidor (LUSTOSA, 2014).

Deste modo, o processo de industrialização brasileiro e a inserção do país no mercado internacional estiveram associados à maior degradação ambiental, mas este modelo também surtiu reflexos no mercado de trabalho. Barcellos (2001) observou que, nos anos 1990, este tipo de ingresso no contexto internacional vinha criando condições de trabalho com acentuada exposição aos riscos industriais, uma vez que se buscou o lucro em detrimento da saúde dos trabalhadores, das populações e do meio ambiente. Do mesmo modo, Young (2014) mostrou que este modelo econômico reforçou a exclusão social, visto que o crescimento do emprego e dos salários é menor nos setores intensivos em recursos naturais e em emissões do que nos outros. Essas atividades são intensivas em capital com baixa demanda por mão de obra e têm sua competitividade baseada no baixo custo de matérias-primas e energia. A agricultura, por exemplo, é o setor que vem desempregando mais no Brasil por causa do monocultivo mecanizado. Entre 1995/99 e 2005/09, a participação do emprego agrícola no emprego total caiu de $24,6 \%$ para $16,1 \%$. Além disso, o setor primário é refém da oscilação dos preços das commodities no mercado internacional.

Em termos comparativos, na Tabela 1 podemos observar que o emprego na agropecuária, embora tenha crescido entre 1997 e 2007, teve uma participação no emprego total inferior a outros setores como os serviços, a indústria de transformação e a administração pública, nos quais se concentraram a maioria dos trabalhadores. 
Tabela 1: Distribuição do emprego por setor de atividade em números, 1997-2007

\begin{tabular}{c|c|c|c}
\cline { 2 - 4 } & 1997 & 2002 & 2007 \\
\hline Extrativa Mineral & 105.830 & 122.806 & 185.444 \\
\hline Ind. Transformação & 4.703 .756 & 5.356 .159 & 7.802 .167 \\
\hline Serv. Ind. Ut. Pública & 332.051 & 319.068 & 364.667 \\
\hline Construção Civil & 1.162 .045 & 1.048 .251 & 1.617 .989 \\
\hline Comércio & 3.688 .782 & 5.119 .479 & 6.840 .915 \\
\hline Serviços & 7.662 .212 & 9.378 .566 & 11.935 .782 \\
\hline Administração Pública & 5.441 .855 & 6.991 .973 & 8.198 .396 \\
\hline Agropecuária & 997.892 & 1.207 .672 & 1.382 .070 \\
\hline Total & 24.104 .428 & 29.544 .927 & 37.607 .430 \\
\hline
\end{tabular}

Fonte: Silva e Monte (2011)

Kupfer et al. (2012) apresentaram uma análise do emprego mais detalhada. Para os autores, a abertura comercial, embora tenha gerado um ciclo expansivo das exportações nos anos 2000, foi pouco dinâmica quanto à geração de emprego e renda. Os empregos diretos associados às exportações foram apenas $5 \%$ do emprego total e cresceram apenas $2 \%$ entre 2002 e 2008, taxa inferior ao crescimento do emprego total de $18 \%$ e das exportações de $200 \%$. Além disso, $67 \%$ desses empregos são de baixa qualificação. Em termos setoriais, os setores que utilizam mais trabalho de baixa qualificação são as atividades agrícolas e a pesca.

Apesar deste cenário pessimista levantado sobre o modelo econômico atual brasileiro, Young (2014) aponta janelas de oportunidades de geração de emprego e renda associadas à Economia Verde. No setor energético, por exemplo, há potencial na geração de eletricidade de obtenção de fertilizantes orgânicos a partir da biomassa; o crescimento da produção eólica tem sido significativo, permitindo não só economia de água, como também criação de postos de trabalho, especialmente na produção dos equipamentos; e a criação e manutenção das Unidades de Conservação, que estão em expansão, chegando a $15 \%$ do território nacional; além de evitar emissões, exigem recursos humanos.

\section{Metodologia}

Neste trabalho, foi pesquisado o número de empregados formais ocupados em atividades econômicas brasileiras vinculadas a efeitos ambientais entre 2007 e 
2014, a partir da Classificação Nacional de Atividades Econômicas (CNAE 2.0) do Instituto Brasileiro de Geografia e Estatísticas (IBGE). Para tanto, foi necessário realizar a seleção das atividades conforme critério ambiental e a apresentação destas a partir dos códigos da CNAE 2.0.

Como nenhuma tipologia setorial existente atendia às necessidades do trabalho, para a seleção e classificação das atividades econômicas que possuem interfaces ambientais, foram utilizados três critérios: 1) a intensidade na extração dos recursos naturais; 2 ) a intensidade de poluição emitida durante o processo produtivo da indústria de transformação; e 3) o efeito ambiental positivo das atividades diretamente envolvidas com a preservação ambiental. Sob essa orientação, foram extraídas categorias de atividades a partir de três classificações conhecidas pela literatura internacional e nacional:

\section{1) Classificação de bens segundo intensidade tecnológica:}

Esta classificação foi realizada pela Comissão Econômica para América Latina e Caribe (CEPAL), a partir do trabalho de Lall (2000), com objetivo de determinar a intensidade tecnológica das exportações dos países em desenvolvimento ${ }^{3}$. Sua estrutura apresenta as seguintes categorias: bens primários, bens industrializados (manufaturas intensivas em recursos naturais, de baixa tecnologia, de média tecnologia e de alta tecnologia) e outras transações (LIMA; ALVAREZ, 2011).

Desta estrutura foi selecionado o primeiro grupo de bens: os primários. Isto porque vários estudos consideram a especialização voltada às exportações de bens primários como meio de intensificação da extração predatória dos recursos naturais, causando o conhecido efeito escala (negativo do ponto de vista ambiental) (SCHAPER, 1999; MAZZERO, 2012).

2) Classificação das Indústrias Ambientalmente Sensíveis (IAS) e Indústrias Limpas (IL):

No que se refere à classificação das indústrias ambientalmente sensíveis ("sujas") e limpas, foi utilizada a definição realizada por Low e Yeats (1992), que se baseia no critério de gastos dispendidos no controle da poluição e apresenta os setores conforme códigos de comércio internacional. As indústrias siderúrgica, química, de papel e celulose e de minerais não metálicos se enquadram no primeiro grupo, enquanto a têxtil, máquinas e aparelhos elétricos, equipamentos de transporte e de medição, no segundo.

Da mesma forma que as atividades anteriores, na maioria dos estudos que se utiliza desta classificação, volta-se à discussão de comércio internacional, porém,

\footnotetext{
Também baseada em Pavitt (1984).
} 
aqui, no intuito de identificar o impacto ambiental da especialização da pauta exportadora do país (SCHAPER, 1999; MAZZERO, 2012; OLIVEIRA, 2014).

3) Classificação das atividades diretamente relacionadas com a preservação ambiental:

Aqui foi utilizada a tipologia de emprego verde sugerida por Bakker e Young (2011), que apresentaram os códigos da CNAE 2.0 referentes às atividades diretamente relacionadas à preservação ambiental e que envolvem gastos públicos e privados. Estas incluem: captação, tratamento e distribuição de água e esgoto; coleta, tratamento e disposição de resíduos sólidos; descontaminação; atividades administrativas e serviços relacionados ${ }^{4}$.

Com relação à apresentação dos códigos em CNAE 2.0, como a caracterização das atividades incluídas nos itens 1 e 2 acima, a partir de códigos internacionais de comércio Standard International Trade Classification (SITC), foi feito um esforço metodológico no sentido de estabelecer uma correspondência entre esses códigos e a CNAE 2.0, por meio dos códigos do Harmonized Commodity Description and Coding System (HS). Nesta etapa, foram utilizadas as classificações de Oliveira (2014) e Ovalle (2008) de STIC rev.4 para HS 2007 e a tabela de conversão do IBGE de HSO7 para CNAE 2.0. Tal classificação deu-se exclusivamente pela descrição das atividades econômicas e encontra-se no anexo.

O período selecionado se justifica pela disponibilidade das informações necessárias à realização da pesquisa: o ano de 2007 refere-se à edição da CNAE 2.0, classificação que também apresenta compatibilidade com a versão 2007 do HS; o ano de 2014 representou o período mais recente no fornecimento dos dados de emprego.

A partir deste refinamento metodológico, foram levantados dados de emprego (pessoal ocupado em 31 de dezembro de cada ano), a partir da CNAE 2.0, na Relação Anual de Informações Sociais (RAIS) disponível no site do Ministério do Trabalho (MTE). Vale observar que esta base se trata de registros administrativos. Como forma de tratamento dos dados, foram investigados a evolução desses empregos em cada setor, a taxa de crescimento anual, a participação do emprego setorial no emprego total, o nível de escolaridade desses empregados e o rendimento em unidades de salário mínimo.

\footnotetext{
Os autores oferecem mais duas categorias de atividades: atividades limpas com potencial de esverdeamento, como pesquisa e desenvolvimento, administração pública e educação e atividades sujas que dependem de inovações intra-setoriais cuja participação do emprego verde é baixa, que incluem agropecuária, indústria, comércio, serviços, construção e transporte. Essas classificações não foram utilizadas, porque as com potencial de esverdeamento envolvem segmentos muito distantes dos aspectos ambientais e as sujas não diferenciam o tipo de impacto - se de extração, de poluição industrial e seus diferentes graus.
} 
Esta metodologia tem a pretensão de oferecer uma nova classificação de atividades econômicas de acordo com o critério ambiental. De modo complementar, esta tipologia, ao permitir a correspondência entre códigos de comércio internacional e a CNAE 2.0, fornece possibilidades de relacionar variáveis comerciais com variáveis domésticas, a saber, o valor da produção e o número de empregados. Isso permitiria avaliar efeitos domésticos de políticas comerciais, por exemplo. Os detalhamentos destas categorias e seus respectivos códigos encontram-se em anexo, ao final do artigo.

\section{Resultados}

Entre 2007 e 2014, o emprego total formal no Brasil cresceu 30\%, tendo 2007 como o ano base. Com relação à participação do emprego nas atividades selecionadas, podemos observar que, isoladamente, houve um destaque para o emprego nas indústrias ambientalmente sensíveis (emprego sujo), que se manteve em torno de $4 \%$ do emprego total no período. De forma agregada, verificou-se uma concentração nas atividades predatórias do ponto de vista ambiental, em torno de $7 \%$ no período, pois $4 \%$ dos empregados estiveram alocados nas indústrias sujas, que emitem poluição durante o processo produtivo, e $3 \%$ nas atividades primárias, que promovem a extração dos recursos naturais. Contudo, a participação do emprego nesses setores caiu mais do que nos outros, bem como o crescimento, tomando 2007 como ano base (ver Tabela 1 e Gráfico 1).

Em contrapartida, embora a participação do emprego verde no emprego total, em 2014, tenha ocupado o terceiro lugar, com 3,37\%, observou-se um crescimento de $21 \%$ no número desses postos de trabalho desde 2007. Esse valor foi bastante superior à taxa de crescimento da ocupação nas outras atividades: de 13\% no setor primário e $12 \%$ na indústria limpa e ambientalmente sensível. 


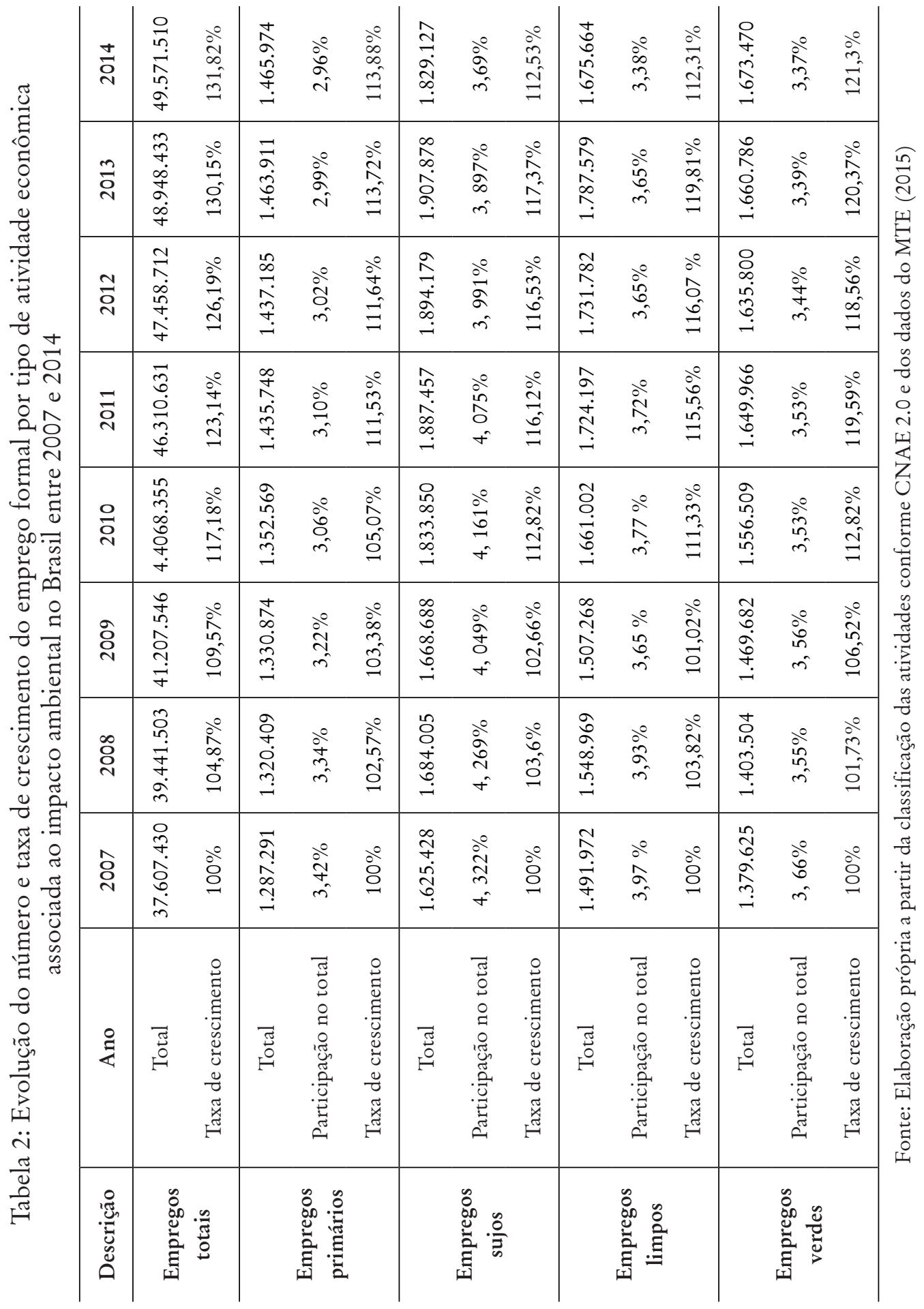


Gráfico 1: Número de empregados em setores de atividades econômicas selecionadas, conforme critério ambiental no Brasil entre 2007 e 2014.

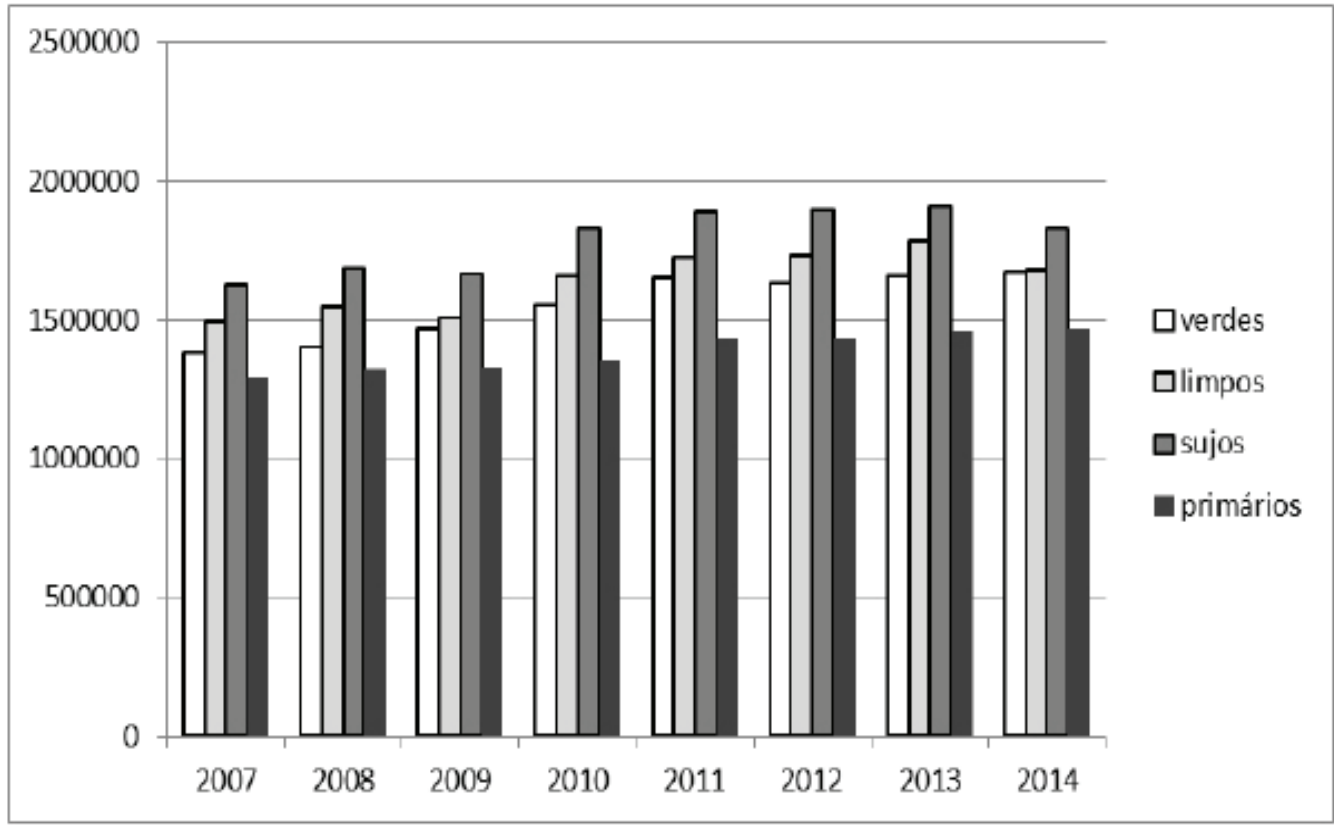

Fonte: MTE (2015)

Assim, apesar da concentração do emprego em atividades que prejudicam o meio ambiente, há um forte potencial de geração de emprego verde no país. Além disso, como podemos ver na Tabela 2 e no Gráfico 2 a seguir, o setor verde empregou os melhores trabalhadores, pois verificou-se uma relação positiva entre número de empregados e nível de escolaridade. Ressalta-se que metade dos pós-graduados empregada nos quatro setores esteve alocada nas atividades de preservação ambiental. Embora pareça ter ocorrido uma queda da participação dos pós-graduados no setor entre 2007 e 2014, registra-se que o número desses trabalhadores aumentou mais de 10 vezes no período, passando de 5148 para 56793. Mesmo concentrados na indústria limpa e ambientalmente sensível, cerca de $30 \%$ dos graduados esteve empregada no setor verde.

No extremo oposto, a situação do setor primário é preocupante por reunir trabalhadores com menores anos de estudo no período: quanto maior o nível de escolaridade, menor o número de empregados. Destaca-se que não só a grande maioria dos analfabetos trabalhou no setor, como também a participação deles cresceu de 68\% para $71 \%$ entre 2007 e 2014 . Além disso, assiste-se à tendência da mecanização na agricultura, o que gera uma séria ameaça de desemprego para essa mão de obra em específico. 
Tabela 3: Número de empregados por nível de escolaridade alocado entre os setores selecionados em 2007 e 2014

\begin{tabular}{c|c|c|c|c}
\hline Nível de Escolaridade/Setor & Primário & IAS* & IL** & Verde \\
\hline \multicolumn{5}{c|}{2007} \\
\hline Analfabeto & 45709 & 8803 & 2492 & 9783 \\
\hline Fundamental & 920469 & 633594 & 423974 & 635975 \\
\hline Médio & 258270 & 753748 & 840710 & 515493 \\
\hline Superior & 52070 & 199167 & 202842 & 187127 \\
\hline Pós-Graduação & 439 & 1677 & 1534 & 5148 \\
\hline Total & 1276957 & 1596989 & 1471552 & 1353526 \\
\hline \multicolumn{5}{|c|}{2014} \\
\hline Analfabeto & 320189 & 58756 & 15784 & 53190 \\
\hline Fundamental & 7034830 & 4517524 & 2951754 & 5161692 \\
\hline Médio & 3013831 & 7482072 & 7919818 & 5189095 \\
\hline Superior & 628524 & 2014022 & 2054352 & 1745084 \\
\hline Pós-Graduação & 9734 & 32208 & 20635 & 56793 \\
\hline Total & 11007108 & 14104582 & 12962343 & 12205854 \\
\hline
\end{tabular}

Fonte: MTE (2015)

(*) IAS Indústria Ambientalmente Sensível

(**) IL Indústria Limpa

Gráfico 2: Nível de Escolaridade dos empregados nos setores selecionados 2007

2014

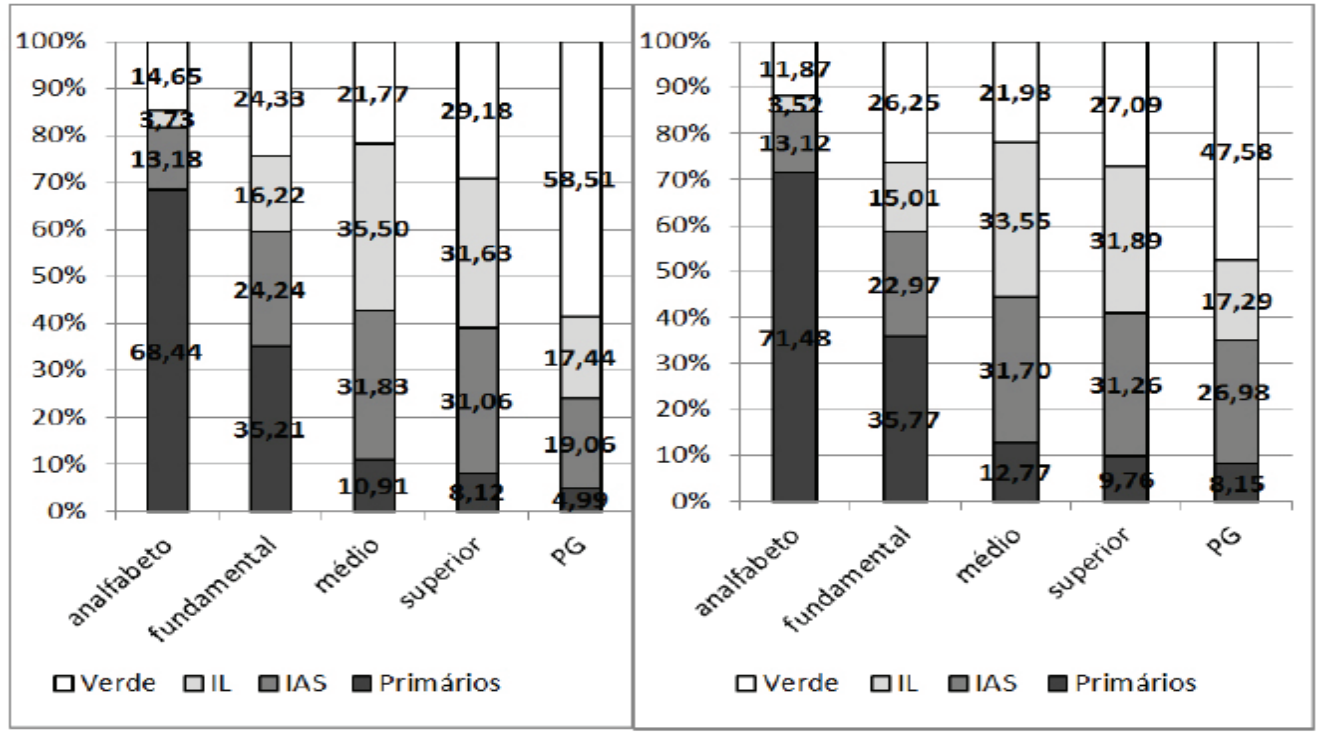

Fonte: MTE (2015) 
Com relação aos rendimentos distribuídos por setor, observou-se uma associação inversa entre maiores salários e número de empregados no setor verde, que se intensificou de 2007 a 2014, como mostra o Gráfico 3. Mais de $30 \%$ dos trabalhadores no setor receberam até um salário mínimo e menos de $10 \%$, mais de 20 salários mínimos. Esta também pareceu ser uma tendência aproximada dos empregados no setor primário. Em contrapartida, os melhores rendimentos se concentraram na indústria ambientalmente sensível e limpa, respectivamente.

Gráfico 3: Rendimento dos empregados nos setores selecionados, em unidades de salário mínimo.

2007

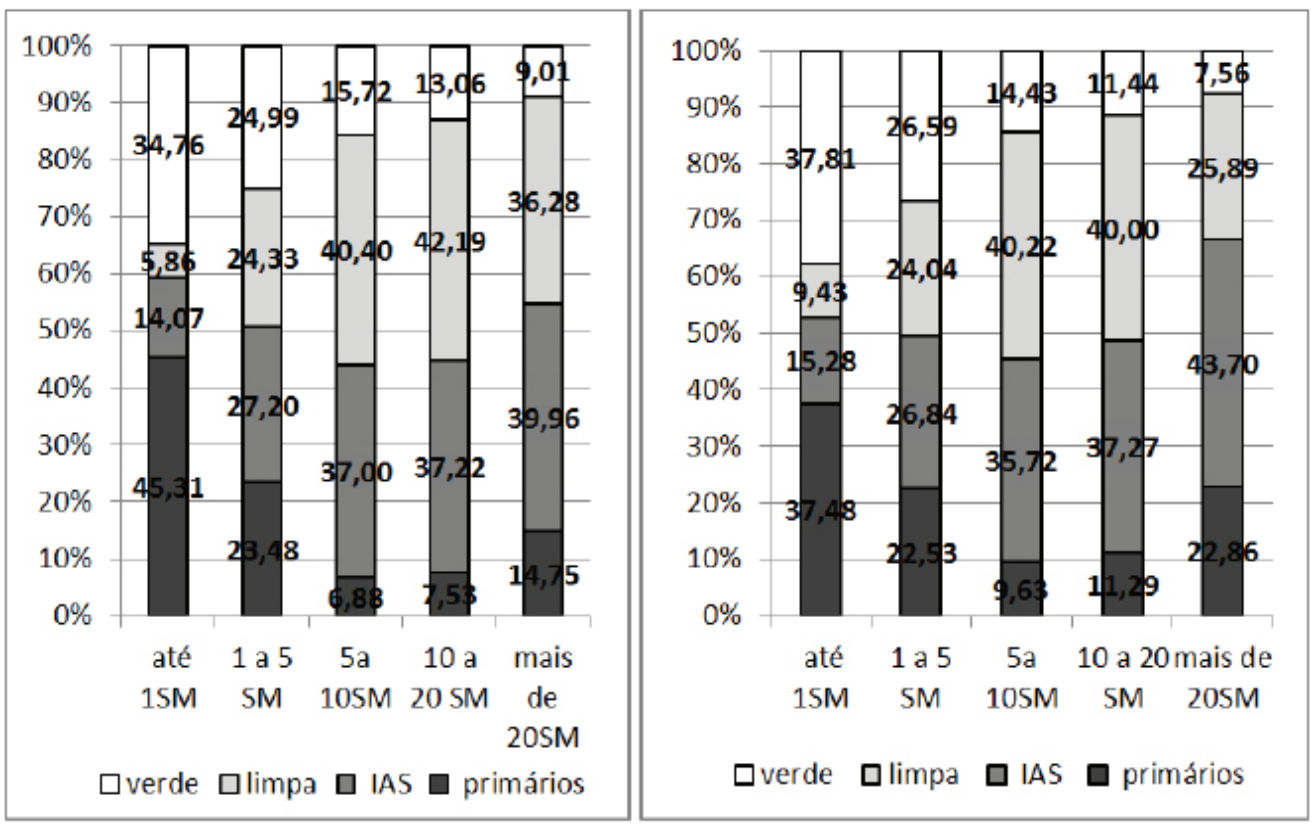

Fonte: MTE (2015)

Dessa forma, existem elementos significativos que têm contribuído para geração de empregos verdes no Brasil, verificados por meio da elevada taxa de crescimento e do alto nível de escolarização. No entanto, esse setor não tem recebido os incentivos financeiros necessários à sua expansão, visto que concentra os salários mais baixos. De outro lado, a elevada participação de empregos em atividades predatórias, do ponto de vista ambiental, exige atenção política em termos de segurança do trabalho, inovações ambientais e novas formas de produção agrícola sustentáveis. 


\section{Considerações finais}

A iniciativa da Economia Verde proporciona novas oportunidades para o investimento e geração de emprego e renda, mas seu aproveitamento não é espontâneo e deve ser promovido por meio de reorientação política. O Brasil, desde seu processo de industrialização, tem caminhado no sentido oposto por atrair indústrias com alto potencial poluidor e se especializar em exportações intensivas em recursos naturais. No entanto, recentemente, tem apresentado algumas janelas de oportunidades na geração de empregos verdes nas atividades de energias alternativas, áreas de preservação, agricultura sustentável, entre outros.

Com o objetivo de identificar e qualificar o emprego nos setores conforme seu impacto ambiental no país, ficou evidente que o mercado de trabalho brasileiro ainda é dependente das atividades ambientalmente predatórias, mas há significativo crescimento e melhora do emprego verde. Embora não sejam os maiores, os empregos verdes são os de maior potencial, não só por conta do elevado crescimento no período, mas também pelo maior número de empregados com elevado nível de escolaridade. Contudo, são os que têm recebido os menores rendimentos no período. Ou seja, foram os que cresceram mais, os melhores, mas os que receberam menos do que os outros setores.

Isso demonstra a necessidade de se atentar à articulação entre políticas de empregos decentes e amigáveis ao meio ambiente e de políticas de estímulo às práticas sustentáveis nas atividades primárias, setor no qual o Brasil apresenta especialização na pauta exportadora, e à inovação tecnológica ambiental nos setores industriais "sujos". Além disso, chama a atenção para incentivos financeiros à expansão de atividades de preservação ambiental no Brasil, no intuito de promoção da Economia Verde como redirecionamento do desenvolvimento do país.

Podemos elencar algumas sugestões de orientações de políticas para promover, de forma planejada, a transição para uma Economia Verde - e geração de emprego verde - no Brasil. Por exemplo, focar no planejamento energético de modo a ampliar a produção de energia renovável, criar centros de Pesquisa e Desenvolvimento (P\&D) para desenvolver tecnologias ambientais e motivar a segurança social trabalhista na área de reciclagem (BETINI, 2013; KON; SUGAHARA, 2012).

Para finalizar, algumas lacunas encontradas no trabalho permitem a sugestão de novas pesquisas, a saber: investigar os determinantes do emprego verde, com ênfase nas relações entre regulação ambiental, tecnologia ambiental e os postos de trabalho; identificar a indústria verde no Brasil e contabilizar o número de empregados nela ocupado; discutir os efeitos domésticos - produção e empregos - decorrentes da promoção de produtos brasileiros no mercado internacional, classificados conforme impacto ambiental. 


\section{Referências}

BAKKER, L. B.; YOUNG, C. E. F. Caracterização do Emprego Verde no Brasil. In: IX Encontro da Sociedade Brasileira de Economia Ecológica, Belém, PA, 2011.

BARCELLOS, F. C. A Indústria Nacional e seu potencial Poluidor. In: IV Encontro Nacional da Sociedade Brasileira de Economia Ecológica, Belém, PA, 2001.

BETINI, R. Development with Green job, renewable energy and sustainability and Power quality. In: International Conference on renewable energies and power quality, Bilbao, Spain, march 2013. crossrefhttps://doi.org/10.24084/repqj11.217

GRAMKOW, C. L. Da restrição externa às emissões de gases do efeito estufa: uma análise da insustentabilidade econômica e ambiental do atual modelo econômico brasileiro. 2011. 272f. Dissertação (Mestrado em Economia) - Instituto de Economia, Universidade Federal do Rio de Janeiro, Rio de Janeiro, 2011.

HETTIGE, H.; MARTIN, P.; SINGH, M.; WHEELER, D., 1995. The Industrial Pollution Projection System. Policy Research Department, Policy Research Working Paper, 1431, The World Bank.

IBGE - Instituto Brasileiro de Geografia e Estatística, 2007. Classificação Nacional de Atividades Econômicas - CNAE 2.0. Comissão Nacional de Classificação. Disponível em: <http://www.ibge.gov.br>. Acesso em: 05 mar. 2015.

INSTITUTO BRASILEIRO DE GEOGRAFIA E ESTATÍSTICA - IBGE. Disponível em: <http://ibge.gov.br>. Acesso em: 07 mai. 2015.

KON, A.; SUGAHARA, C. Sustentabilidade e empregos verdes no Brasil. Curitiba: Editora APPRIS, 2012.

KUPFER, D.; CASTILHO, M.; DWECK, E.; NICOLL, M. Diferentes parceiros, diferentes padrões: comércio e mercado de trabalho no Brasil nos anos 2000. Santiago: CEPAL, Série Comércio Internacional, n. 18, outubro/2012.

LALL, S. The technological structure and performance of developing country manufactured exports, 1985-1998. Oxford: University of Oxford, Queen Elizabeth House, 2000. (Série QEH Working Papers, No. QEHWPS44).

LIMA, J. E. D.; ALVAREZ, M. Manual de comércio exterior y política comercial: nociones básicas, clasificaciones e indicadores de posición y dinamismo. Santiago de Chile: Naciones Unidas: CEPAL, 2011. 
LOW, P.; YEATS, A. Dirty Industries Migrate? In: LOW, P. (Ed.). International Trade and the Environment. Washington, DC: The World Bank, 1992, p. 89-104. Discussion Paper 159.

LUSTOSA, M. C. O parceiro comercial é relevante? Uma análise do padrão de especialização ambiental do comércio exterior da indústria brasileira. Ensaios FEE, Porto Alegre, v. 35, n. 2, p. 393-416, dez./2014.

MAZZERO, M. F. Análise ambiental do comércio bilateral Brasil-China. 2012. 79f. Monografia (Graduação em Economia) - Faculdade de Ciências e Letras, Universidade Estadual Paulista, Araraquara, 2012.

MINISTÉRIO DO TRABALHO E DO EMPREGO (MTE). Disponível em <www.mte.gov.br>. Acesso em: 05 mar. 2015.

MONTEIRO, M. I.; CORRÊA FILHO, H. R.; SIQUEIRA, C. E. Green Jobs, Green Economy - Ampliando as Possibilidades de Desenvolvimento Sustentável. In: VILARTA, R.; GUTIERREZ, G. L.; MONTEIRO, M. I. (Org.). Qualidade de vida: evolução dos conceitos e práticas do século XXI. Campinas: IPES, 2010.

OIT - Organização Internacional do Trabalho - Escritório no Brasil. OIT. 2009. Empregos Verdes no Brasil: Quantos são, onde estão e como evoluirão nos próximos anos.

OLIVEIRA, T. D. Análise do perfil do comércio entre China e países Latino Americanos. 2014. 140f. Dissertação (Mestrado em Economia) - Faculdade de Ciências e Letras, Universidade Estadual Paulista, Araraquara, 2014.

OECD. Organization for Economic Co-operation and Development. Policy Responses to the Economics Crisis: investing in innovation for long-term growth. June, 2009.

OVALLE, A. Classificaciones estadísticas internacionales incorporadas en el Banco de Datos Del Comercio Exterior da America Latina y El Caribe de la Cepal (Rev. 3). Santiago de Chile: Naciones Unidas - Cepal, 2008. Seria Cuadernos estadísticos de la Cepal, n. 36.

PAVITT, K. Sectoral patterns of technical change: towards a taxonomy and a theory. Research Policy, [S. 1.], v. 13, p. 343-373, dez. 1984. Disponível em: <http:// www.sciencedirect.com/science/article/pii/0048733384900180 >. Acesso em: 1 jul. 2012. 
SILVA, J. A. R.; MONTE, P. A. Dinâmica regional e setorial do emprego no Brasil: 1997 a 2007. Revista de Economia, v. 37, n. 2 (ano 35), p. 80-108, mai./ago. 2011.

SIMA, V.; GEORGIANA, G. I. Labour market trends in Romania in the context of Green economy. Annals of the Constantin Brâncuşi University of Târgu Jiu, Economy Series, Special Issue/2014 - Information society and sustainable development.

SCHAPER, M. Impactos Ambientales de los Cambios en la Estructura Exportadora em Nueve Países de America Latina y El Caribe: 1980-1995. Santiago de Chile: Naciones Unidas - Cepal, 1999. Serie Medio Ambiente y Desarrolo, n. 19.

United Nations Environment Programme. UNEP. 2008. Background Paper on Green Jobs.

YOUNG, C. E. F.; LUSTOSA, M. C. J. Meio Ambiente e Competitividade na Indústria Brasileira. Revista de Economia Contemporânea, v. 5, Edição Especial, Rio de Janeiro: IE/UFRJ, 2001, p. 231-259.

YOUNG, C. E. F. Política Ambiental e Economia Verde no Brasil. In: EARP, F. S.; BASTIAN, E. F.; MODENESI, A. M. (Org.). Como vai o Brasil? A Economia Brasileira no Terceiro Milênio. IMÃ Editora Ebook, 2014. Disponível em <http://comovaiobrasil.pressbooks.com>. Acesso em: 15 nov. 2015. 


\section{Anexo}

\begin{tabular}{|c|c|c|c|}
\hline $\begin{array}{l}\text { SETOR DE } \\
\text { ATIVIDADE }\end{array}$ & SITC REV.4 & HSO7 & CNAE $2.0(2007)$ \\
\hline \multicolumn{4}{|l|}{$\begin{array}{l}\text { ATIVIDADE DE BENS } \\
\text { PRIMÁRIOS }^{1}\end{array}$} \\
\hline $\begin{array}{l}\text { Carnes, leite e ovos e } \\
\text { pescados }\end{array}$ & $\begin{array}{l}001,011,012 \\
022,025,034 \\
036\end{array}$ & $\begin{array}{l}\text { 0101, 0102, 0103, 0104, 0105, 0106, } \\
0201,0202,0203,0204,0205,0206, \\
0207,0208,0401,0402,0403,2105, \\
0404,0407,0408,3502,0301,0302, \\
0303,0304,0306,0307\end{array}$ & $\begin{array}{l}0152-1,0151-2,0154-7, \\
0153-9,0155-5,0159-8, \\
0311-6,0321-3,0322-1, \\
0312-4\end{array}$ \\
\hline Cereais & $\begin{array}{l}041,042,043 \\
044,045\end{array}$ & $\begin{array}{l}\text { 1001, 1002, 1003, 1004, 1005, 1006, } \\
1007,1008\end{array}$ & $0111-3$ \\
\hline Legumes e frutas & 054,057 & $\begin{array}{l}\text { 0701, 0702, 0703, 0704, 0705, 0706, } \\
\text { 0707, 0708, 0709, 0710, 0711, 0713, } \\
\text { 0714, 1210, 0801, 0802, 0803, 0804, } \\
0805,0806,0807,0808,0809,0810 \\
0813\end{array}$ & $\begin{array}{l}0119-9,0121-1,0133-4 \\
0139-3,0131-8,0132-6 \\
0122-9\end{array}$ \\
\hline $\begin{array}{l}\text { Café, chá, cacau e espe- } \\
\text { ciarias }\end{array}$ & 071,075 & $\begin{array}{l}0901,0902,0903,0904,0905,0906, \\
0907,0908,0909,0910,2101,1801 \\
1802,1803,1804,1805\end{array}$ & 0134-2, 0135-1 \\
\hline $\begin{array}{l}\text { Ração animal, preparados } \\
\text { comestíveis }\end{array}$ & 081, 091 & $\begin{array}{l}1213,1214,2301,2302,2303,2304 \\
2305,2306,2307,2308,2309,1517\end{array}$ & $\begin{array}{l}1069-4,1064-3,1062-7 \\
1061-9,1065-1,1043-1 \\
1063-5\end{array}$ \\
\hline Tabaco & 121 & 2401 & 0114-8 \\
\hline Couros e peles & 211,212 & $4101,4102,4103,4301,4115$ & $0170-9$ \\
\hline $\begin{array}{l}\text { Sementes e frutos oleagi- } \\
\text { nosos }\end{array}$ & 222,223 & $\begin{array}{l}\text { 1201, 1202, 1203, 1204, 1205, 1206, } \\
1207,1208\end{array}$ & 0115-6, 0116-4, \\
\hline $\begin{array}{l}\text { Borracha, madeira, fibras } \\
\text { têxteis naturais }\end{array}$ & $\begin{array}{l}231,244,245 \\
246,261,263 \\
268\end{array}$ & $\begin{array}{l}1404,4001,4401,4402,4501,4502, \\
5001,5002,5003,5101,5102,5103 \\
5104,5105,5201,5202,5203\end{array}$ & $0112-1,0220-9,0210-1$ \\
\hline $\begin{array}{l}\text { Fertilizantes e minerais } \\
\text { brutos }\end{array}$ & $\begin{array}{l}272,273,274 \\
277,278\end{array}$ & $\begin{array}{l}2501,2502,2503,2504,2505,2506, \\
2507,2508,2509,2510,2511,2512, \\
2513,2514,2515,2516,2517,2518, \\
2519,2520,2521,2524,2525,2526, \\
2528,2529,2530,2619,2618,2621, \\
3101,3102,7102,7105\end{array}$ & $\begin{array}{l}\text { 0892-4, 0891-6, 0899-1, } \\
0810-0,0893-2\end{array}$ \\
\hline Minérios & $\begin{array}{l}281,283,284 \\
285,286,287 \\
289\end{array}$ & $\begin{array}{l}2601,2602,2603,2604,2605,2606, \\
2607,2608,2609,2610,2611,2612, \\
2613,2614,2615,2616,2617,2818 \\
7112,7401,7501\end{array}$ & $\begin{array}{l}0710-3,0723-5,0729-4, \\
0721-9,0722-7,0725-1 \\
0724-3\end{array}$ \\
\hline Carvão, petróleo e gás & $\begin{array}{l}321,333,342 \\
343,344,345\end{array}$ & $2701,2709,2711,2705$ & $0500-3,0600-0$ \\
\hline
\end{tabular}


(continua)

\begin{tabular}{|c|c|c|c|}
\hline $\begin{array}{l}\text { ATIVIDADE } \\
\text { INDUSTRIAL }\end{array}$ & & & \\
\hline $\begin{array}{l}\text { INDÚSTRIA } \\
\text { AMBIENTALMENTE } \\
\text { SENSÍVEL }{ }^{2}\end{array}$ & & & \\
\hline $\begin{array}{l}\text { Indústria do couro e produ- } \\
\text { tos de couro, substitutos do } \\
\text { couro e pele, com exceção de } \\
\text { calçados e vestuário }\end{array}$ & $\begin{array}{l}611,612,613 \\
831\end{array}$ & $\begin{array}{l}\text { 4104, 4105, 4106, 4107, 4112, 4113, } \\
4114,4115,4201,4202,4203,4205 \\
4302,9605\end{array}$ & $1510-6,1529-7,1521-1$ \\
\hline $\begin{array}{l}\text { Indústria do papel e } \\
\text { produtos de papel }\end{array}$ & $251,641,642$ & $\begin{array}{l}4701,4702,4703,4704,4705,4706, \\
4707,4801,4802,4803,4804,4805, \\
4806,4807,4808,4809,4810,4811, \\
4812,4813,4814,4816,4817,4818, \\
4819,4820,4822,4823\end{array}$ & $\begin{array}{l}1710-9,1721-4,1722-2, \\
1733-8,1749-4,1731-1, \\
1741-9,1742-7,1731-1, \\
1732-0\end{array}$ \\
\hline $\begin{array}{l}\text { Indústria de produtos } \\
\text { químicos }\end{array}$ & $\begin{array}{l}232,266,267, \\
511,512,513, \\
514,515,516, \\
522,523,524, \\
525,531,532, \\
562,571,572, \\
573,574,575, \\
579,582,583, \\
591,598,599\end{array}$ & 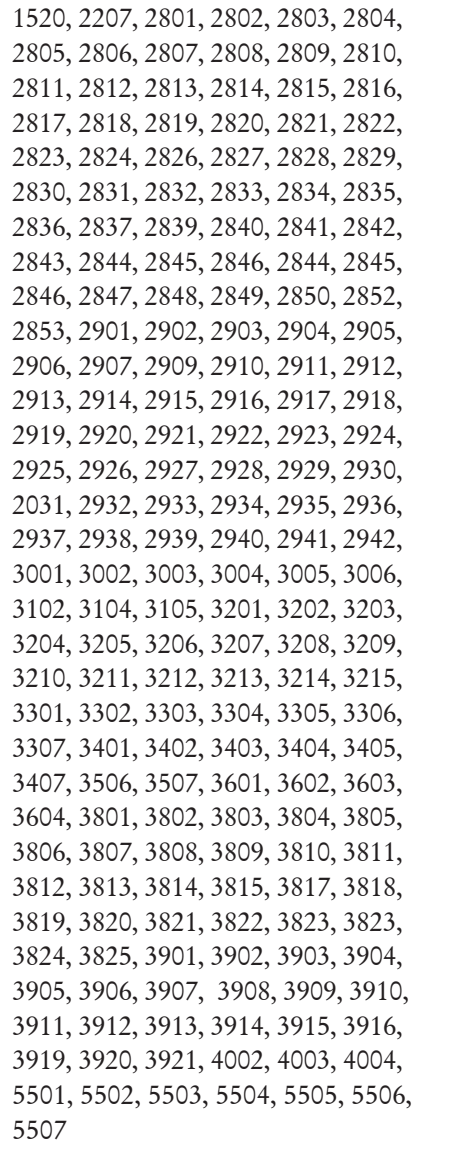 & $\begin{array}{l}2011-8,2019-3,2029-1, \\
2014-2,2099-1,2012-6, \\
2051-7,2062-2,2021-5, \\
2022-3,2061-4,2093-2, \\
2073-8,2110-6,2032-1, \\
2094-1,2121-1,2031-2, \\
2122-0,2123-8,2071-1, \\
2013-4,2033-9,2072-0, \\
2063-1,2091-6,2052-5, \\
2040-1\end{array}$ \\
\hline Refinaria de petróleo & 334,335 & $2706,2707,2708,2710,2712,2713,2715$ & $1910-1,1921-7,1922-5$ \\
\hline $\begin{array}{l}\text { Indústria de produtos de } \\
\text { borracha }\end{array}$ & $621,625,629$ & $\begin{array}{l}4005,4006,4007,4008,4009,4010 \\
4011,4012,4013,4014,4016,4017\end{array}$ & 2219-6, 2212-9, 2211-1 \\
\hline
\end{tabular}


(continua)

\begin{tabular}{|c|c|c|c|}
\hline $\begin{array}{l}\text { Indústria de outros produ- } \\
\text { tos minerais não metálicos }\end{array}$ & $661,662,663$ & $\begin{array}{l}2522,2523,3816,6801,6802,6803 \\
6804,6805,6806,6807,6808,6809 \\
6810,6811,6812,6813,6814,6815 \\
6901,6902,6903,6905,6906,6907, \\
6908,6909,6914\end{array}$ & $\begin{array}{l}2392-3,2341-9,2320-6, \\
2391-5,2399-1,2330-3, \\
2342-7,2349-4\end{array}$ \\
\hline $\begin{array}{l}\text { Indústria de metalurgia de } \\
\text { ferro e aço }\end{array}$ & $\begin{array}{l}671,672,673 \\
674,675,676 \\
677,678,679\end{array}$ & $\begin{array}{l}7201,7202,7203,7205,7206,7207, \\
7208,7209,7210,7211,7212,7213, \\
7214,7215,7216,7217,7218,7219, \\
7220,7221,7222,7223,7224,7225, \\
7226,7227,7228,7229,7301,7302, \\
7303,7304,7305,7306,7307\end{array}$ & $\begin{array}{l}2411-3,2412-1,2421-1, \\
2422-9,2424-5,2423-7, \\
2431-8,2439-3,2451-2\end{array}$ \\
\hline $\begin{array}{l}\text { Indústria metalúrgica de } \\
\text { minerais não ferrosos }\end{array}$ & $\begin{array}{l}283,284,288 \\
681,682,683 \\
684,685,686 \\
687,689,971\end{array}$ & $\begin{array}{l}2603,2604,2620,7401,7402,7403, \\
7404,7405,7406,7407,7408,7409, \\
7411,7412,7501,7502,7503,7505, \\
7506,7507,7601,7602,7603,7604, \\
7605,7606,7607,7608,7609,7801, \\
7802,7804,7901,7902,7903,7904, \\
7905,8001,8002,8003,7106,7107, \\
7108,7109,7110,7111,7112,8101, \\
8102,8103,8104,8105,8106,8107, \\
8108,8109,8110,8111,8112,8113\end{array}$ & $\begin{array}{l}2449-1,2443-1,2441-5 \\
2442-3,2452-1\end{array}$ \\
\hline $\begin{array}{l}\text { Indústria de produtos de } \\
\text { metal, exceto máquinas e } \\
\text { equipamentos }\end{array}$ & $\begin{array}{l}691,692,693 \\
694,695,696 \\
697,699,812 \\
813\end{array}$ & $\begin{array}{l}\text { 6910, 7308, 7309, 7310, 7311, 7312, } \\
7313,7314,7315,7316,7317,7318, \\
7319,7320,7321,7322,7323,7324, \\
7325,7326,7413,7415,7418,7419, \\
7508,7610,7611,7612,7613,7614, \\
7615,7616,7806,7807,8007,8201, \\
8202,8204,8205,8206,8207,8208, \\
8209,8210,8211,8212,8213,8214, \\
8215,8301,8302,8303,8306,8307, \\
8308,8309,8310,8311,8403,8513, \\
9405\end{array}$ & $\begin{array}{l}2511-0,2512-8,2513-6, \\
2521-7,2591-8,2592-6, \\
2599-3,2593-4,2531-4, \\
2532-2,2542-0,2543-8, \\
2541-1,2522-5\end{array}$ \\
\hline INDÚSTRIA LIMPA ${ }^{3}$ & & HS 07 & CNAE 2.0 \\
\hline Indústria Têxtil & $\begin{array}{l}651,652,653 \\
654,655,656 \\
657,658,659\end{array}$ & $\begin{array}{l}5004,5005,5006,5007,5106,5107, \\
5108,5109,5110,5111,5112,5204, \\
5205,5206,5207,5208,5209,5210, \\
5211,5212,5306,5307,5308,5309, \\
5310,5401,5402,5403,5404,5405, \\
5406,5407,5408,5508,5509,5510, \\
5511,5512,5513,5514,5515,5516, \\
5601,5602,5603,5604,5605,5606, \\
5607,5608,5609,5701,5702,5703, \\
5704,5705,5801,5802,5804,5805, \\
5806,5807,5808,5809,5810,5811, \\
5901,5902,5903,5904,5905,5906, \\
5907,5908,5909,5910,5911,6001, \\
6002,6003,6004,6005,6006,6301, \\
6302,6303,6304,6305,6306,6307, \\
6308,6501,6502,7019\end{array}$ & $\begin{array}{l}1312-0,1322-7,1314-6, \\
1311-1,1321-9,1313-8, \\
1323-5,1354-5,1359-6, \\
1353-7,1352-9,1351-1, \\
1330-8,1340-5\end{array}$ \\
\hline
\end{tabular}


(continua)

Indústria de máquinas, exceto elétricas

Indústria de máquinas e
aparelhos elétricos,
aparelhos e materiais
$\begin{aligned} & \text { Indústria de equipamento } \\ & \text { de transporte }\end{aligned}$

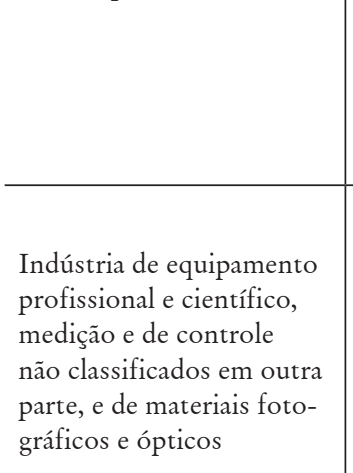

$711,712,713$ $714,718,721$, $722,723,724$, $725,726,727$ $728,731,733$, $735,737,741$, $742,743,744$, $745,756,747$, 748, 749, 751, 752,759
$8401,8402,8404,8405,8406,8407$, $8408,8409,8410,8411,8412,8413$, $8414,8415,8416,8417,8418,8419$, $8420,8421,8422,8423,8424,8425$, $8426,8427,8428,8429,8430,8431$, $8432,8433,8434,8435,8436,8437$, $8438,8439,8440,8441,8442,8443$, $8444,8445,8446,8447,8448,8449$, $8450,8451,8452,8453,8454,8455$, $8456,8457,8458,8459,8460,8461$, $8462,8463,8464,8465,8466,8467$, $8468,8469,8470,8471,8472,8473$, $8474,8475,8476,8477,8478,8479$, $8480,8481,8482,8483,8484,8486$, $8487,8514,8515,8709$

716, 761, 762, 764, 771, 772, $773,774,775$, 776, 778

$781,782,783$ 784, 785, 786, 791, 792, 793

$871,872,873$, $874,881,882$, $883,884,885$
$8501,8502,8503,8504,8505,8506$, $8507,8508,8509,8510,8511,8512$, $8516,8527,8528,8530,8531,8532$, $8533,8534,8535,8536,8537,8538$, $8539,8540,8541,8542,8543,8544$, $8545,8546,8547,8548,9022$

8601, 8602, 8603, 8604, 8605, 8606, $8607,8608,8609,8701,8702,8703$, $8704,8705,8706,8707,8708,8711$, $8712,8713,8714,8716,8801,8802$, $8803,8805,8901,8902,8903,8904$, $8905,8906,8907,8908$
3707, 3701, 3702, 3703, 3704, 3705, 3706, 9001, 9002, 9003, 9004, 9005, 9006, 9007, 9008, 9010, 9011, 9012, 9013, 9014, 9015, 9016, 9017, 9018, $9019,9020,9023,9024,9025,9026$, 9027, 9027, 9028, 9029, 9030, 9031,
2822-4, 2840-2, 2821-6, 2812-7, 2829-1, 2869-1, 2815-1, 2811-9, 2813-5, 2862-3, 2854-2, 2866-6, 2852-6, 2861-5, 2864-0, 2863-1, 2865-8, 2833-0, 2851-8, 2832-1, 2832-2, 2824-1, 2814-3, 2825-9

2710-4, 2740-6, 2790-2, 2721-0, 2722-8, 2759-7, 2751-1, 2731-7, 2732-5, 2733-3, 2622-1, 2610-8, 2631-1, 2640-0, 2621-3, 2945-0

3031-8, 3032-6, 2930-1, 2831-3, 2920-4, 2853-4, 2910-7, 2854-2, 2949-2, 2941-7, 2943-3, 2942-5, 2944-1, 3091-1, 3092-0, 3099-7, 3041-5, 3042-3, 3011-3, 3012-1 9032, 9033, 9101, 9102, 9103, 9104, 9105, 9106, 9107, 9108, 9109, 9110, 9111, 9112, 9113, 9114, 9402
2670-1, 3250-7, 2651-5, 2660-4, 2652-3

\begin{tabular}{l|l|l}
\hline $\begin{array}{l}\text { ATIVIDADE DE } \\
\text { PRESERVAÇÃO } \\
\text { AMBIENTAL }^{4}\end{array}$ & CNAE 2.0 \\
\hline $\begin{array}{l}\text { ÁGUA, ESGOTO, } \\
\text { ATIVIDADES }\end{array}$ & \\
$\begin{array}{l}\text { DE GESTÃO DE } \\
\text { RESÍDUOS E } \\
\text { DESCONTAMINAÇÃO }\end{array}$ & & \\
\hline $\begin{array}{l}\text { Captação, tratamento e } \\
\text { distribuição de água }\end{array}$ & & \\
\hline $\begin{array}{l}\text { Esgoto e atividades rela- } \\
\text { cionadas }\end{array}$ & $3600-6$ \\
\hline
\end{tabular}




\begin{tabular}{|c|c|}
\hline $\begin{array}{l}\text { Coleta, tratamento e } \\
\text { disposição de resíduos; } \\
\text { recuperação de materiais }\end{array}$ & $\begin{array}{l}3811-4,3812-2,3821-1, \\
3822-0,3831-9,3832-7, \\
3839-4\end{array}$ \\
\hline Descontaminação & $3900-5,4222-7$ \\
\hline $\begin{array}{l}\text { ATIVIDADES AD- } \\
\text { MINISTRATIVAS E } \\
\text { SERVIÇOS COMPLE- } \\
\text { MENTARES }\end{array}$ & \\
\hline $\begin{array}{l}\text { Serviços para edifícios e } \\
\text { atividades paisagísticas }\end{array}$ & $\begin{array}{l}8121-4,8122-2,8129-0, \\
8130-3\end{array}$ \\
\hline $\begin{array}{l}\text { Atividades ligadas ao } \\
\text { patrimônio cultural e } \\
\text { ambiental }\end{array}$ & $9103-1$ \\
\hline $\begin{array}{l}\text { Atividades de organiza- } \\
\text { ções associativas }\end{array}$ & $9430-8,9499-5$ \\
\hline
\end{tabular}

Fonte: Elaboração própria a partir de Alvarez (2011), Ovalle (2008), IBGE (2015) e Bekker, Young (2011)

1) Conforme classificação de bens por intensidade tecnológica, atualizado para SITC revisão 4 a partir de Lima e Alvarez (2011) e Ovalle (2008). Para os propósitos deste trabalho, estas atividades envolvem agricultura, pecuária, produção florestal, pesca e aquicultura e indústria extrativa.

2) Conforme classificação de indústrias ambientalmente sensíveis a partir de Lima e Alvarez (2011) e Ovalle (2008)

3) Conforme classificação de indústrias limpas a partir de Lima e Alvarez (2011) e Ovalle (2008)

4) Conforme classificação de atividades de preservação ambiental - emprego verde - a partir de Bekker e Young (2011) 
